\title{
AVALIAÇÃO DE FORRAGEIRAS DE INVERNO IRRIGADAS SOB PASTEJO
}

\author{
Evaluation of cool season forage species irrigated under grazing \\ Andréia Luciane Moreira1, Ricardo Andrade Reis², Ana Cláudia Ruggieri², \\ Arlindo José Saran Junior ${ }^{4}$
}

\begin{abstract}
RESUMO
O experimento foi conduzido na UNESP - Jaboticabal com o objetivo de obter informações sobre o rendimento de matéria seca (RMS) e composição química das forrageiras de inverno, aveia preta (Avena strigosa Schreb) e triticale (X Triticosecale Wittmack), em plantio direto sob palhada de área com milheto (Pennisetum americanum (L.) K. Schum.) ou híbrido sorgo sudão (Sorghum bicolor (L.) Moench x Sorghum sudanense (Piper) Stapf) submetidas a pastejo. A forragem foi rebaixada por vacas da raça Holandês. O delineamento experimental utilizado foi em blocos casualizados, em arranjo de parcelas subdivididas, sendo analisado nas parcelas as espécies forrageiras e nas sub-parcelas as épocas de pastejo, com quatro repetições. Os tratamentos testados foram: AS: Aveia Preta sobre palhada de sorgo; AM: Aveia preta sobre palhada de milheto; TS: Triticale sobre palhada de sorgo; e, TM: Triticale sobre palhada de milheto. As pastagens apresentaram RMS semelhantes e, em relação às épocas de avaliação observou-se menor rendimento no segundo corte. Foram observados maiores teores de PB e de FDA na forragem colhida no primeiro corte e de hemicelulose no segundo corte, enquanto os valores de FDN não foram diferentes. A forragem de triticale apresentou menor conteúdo de PB e maiores teores de constituintes da parede celular.
\end{abstract}

Termos para indexação: Aveia preta, sistema de plantio direto, sorgo sudão, triticale.

\begin{abstract}
The research was carried out at UNESP - Jaboticabal to evaluate the dry matter yield (YMP), chemical composition of the cool season forage species: oat (Avena strigosa Schreb) and triticale (X Triticosecale Wittmack) no-till seeding in annual summer species cultivated area with pearl millet (Pennisetum americanum (L.) K. Schum.) or sorghum-sudangrass hybrid (Sorghum bicolor (L.) Moench $x$ Sorghum sudanense (Piper) Stapf). The forage was grazed by Holstein cows in rotational stocking system. It was used the completely randomized outline in split plot scheme with four replications. In the first experiment the following treatments were evaluated: AS - oat no-till seeding in sorghum-sudangrass hybrid stubble, AM - oat no-till seeding in pearl millet stubble, TS - triticale no-till seeding in sorghum-sudangrass hybrid stubble, and TM - Triticale no-till seeding in pearl millet stubble. The forages presented similar dry matter evaluation, however the YMP decreased on the second evaluation. It was observed highest crude protein, ADF on the first yield and hemicellulose on the second evaluation. The harvest time did not affect the forage NDF content. Triticale showed lower CP and higher cell wall content compared to the oat forage.
\end{abstract}

Index terms: Bristle oat, no-tillage system seeding, sorghum sudan grass, triticale.

(Recebido em 5 de março de 2007 e aprovado em 19 de julho de 2007)

\section{INTRODUÇÃO}

Atualmente, com as mudanças na economia mundial, tais como, a abertura de mercados, a globalização e tentativa de estabilidade da economia brasileira, as atividades de produção necessitam de melhor performance produtiva com eficiência, para garantir a permanência do produtor na sua atividade. Assim, deve-se buscar produção constante e de baixo custo, para que este possa ser competitivo no mercado global e crescer dentro da sua atividade.
No Brasil Central, durante o inverno, em decorrência da escassez de chuvas associada à baixas temperaturas, ocorre insuficiência de pasto oriundo de gramíneas tropicais, tanto em termos quantitativos, quanto qualitativos para atender ao requerimento animal. É neste período, com o intuito de atender ao contexto econômico atual, que espécies anuais de estação fria adaptadas às regiões temperadas e subtropicais vêm sendo empregadas de diferentes formas com vista à produção de forragem de alto valor nutritivo (ALVIM \& MARTINS, 1986).

\footnotetext{
1Doutora - Agêcnia Paulista de Tecnologia dos Agronegócios/APTA - Pólo Regional Alta Sorocabana - Rodovia Raposo Tavares, Km 561 - Nova Prudente - Cx. P. 298 - 19015-970 - Presidente Prudente, SP - aluciane@aptaregional.sp.gov.br

2Doutor, Professor - Departamento de Zootecnia/DZO - Faculdade de Ciências Agrárias e Veterinárias/FCAV - Universidade Estadual de São Paulo/ UNESP - Via de Acesso Paulo Donato Castelane, s/n - 14884-900 - Jaboticabal, SP - rareis@fcav.unesp.br - Pesquisador CNPq

${ }^{3}$ Doutora, Professora - Departamento de Zootecnia/DZO - Faculdade de Ciências Agrárias e Veterinárias/FCAV - Universidade Estadual de São Paulo/ UNESP - Via de Acesso Paulo Donato Castelane, s/n - 14884-900 - Jaboticabal, SP - acruggieri@fcav.unesp.br

${ }^{4}$ Mestrando - Departamento de Zootecnia/DZO - Faculdade de Ciências Agrárias e Veterinárias/FCAV - Universidade Estadual de São Paulo/UNESP — Via de Acesso Paulo Donato Castelane, s/n - 14884-900 - Jaboticabal, SP - saranjunior@hotmail.com
} 
Dentre as forrageiras anuais de inverno, a aveia (Avena sp.) e o triticale (X Triticosecale Wittmack) destacam-se por apresentarem grande adaptação às condições edafoclimáticas do Centro-Sul do Brasil, permitindo o cultivo nestas regiões (FLOSS, 1988; REIS et al., 1993; STALLKNECHT et al., 1996).

A falta de cultivares adaptados e que apresentem características desejáveis, como alta produção de forragem de elevado valor nutritivo, representa a maior dificuldade enfrentada pelos agropecuaristas na implantação de sistemas de cultivos de inverno. Desta forma, há necessidade de buscar materiais adaptados e que apresentem interações positivas com as condições ambientais do local. Segundo Godoy et al. (1992), no Brasil Central tem-se utilizado a aveia preta (Avena strigosa Schreb) para produção de forragem, contudo as aveias branca (Avena sativa L.) e amarela (Avena byzantina K. Koch) podem ser consideradas de duplo propósito, permitindo a produção de forragem e de grãos. Além da aveia, o triticale pode ser utilizado na produção de feno (STALLKNECTH et al., 1996), sob pastejo, ou substituindo outros cereais como fonte de energia e proteínas na nutrição de monogástricos e ruminantes (VARUGHESE et al., 2002).

O potencial de rendimento forrageiro da aveia é bastante variável em função da espécie utilizada, fertilidade do solo, disponibilidade de água, regime de cortes e época de semeadura (FLOSS, 1988; PEREIRA, 1988; VILELA, 1981).

Quanto à época de semeadura, a CSBPA (1991) recomenda semear de março a abril quando o rendimento de massa é para a obtenção de cobertura verde no solo. Para o rendimento de grãos, as épocas recomendadas variam de acordo com as regiões produtoras e estão no intervalo de meados de maio a meados de julho.

Assim, Cardoso (1977) indica para a região CentroSul, como a melhor época de semeadura, o mês de abril, no entanto, pode ser efetuado em março, com o aproveitamento das últimas chuvas. Entretanto, Leite (1986) sugere os meses de abril e maio como a melhor época de semeadura, pois plantios precoces expõem a cultura ao ataque de doenças.

Dentre os diferentes métodos que podem ser adotados para o rendimento de forrageiras de inverno, o plantio direto torna-se uma ferramenta essencial na intensificação dos sistemas de produção animal, uma vez que proporciona uma melhor utilização do tempo, com redução de gastos com preparo do solo e com a contribuição para a melhoria das condições físicas e químicas do mesmo. Assim, neste trabalho, objetivouse avaliar o rendimento e a composição química de forrageiras de inverno em plantio direto em áreas formadas com milheto ou híbrido sorgo sudão submetidas a pastejo.

\section{MATERIAL E MÉTODOS}

O experimento foi conduzido no setor de Forragicultura da Faculdade de Ciências Agrárias e Veterinárias (FCAV), campus de Jaboticabal - UNESP, situado à Latitude: $21^{\circ} 15^{\prime} 22^{\prime \prime}-\mathrm{S}$ e Longitude: $48^{\circ} 18^{\prime} 58^{\prime \prime}$ W, e altitude média de 595 metros, em solo classificado como Latossolo Vermelho Distrófico típico textura argilosa (ANDRIOLI \& CENTURION, 1999).

Os elementos metereológicos foram obtidos na Estação Agrometereológica do Departamento de Ciências Exatas e os dados referentes às temperaturas máximas, mínimas e médias, bem como os de precipitação e umidade relativa observados durante o período experimental encontram-se Tabela 1.

No experimento foram avaliados os seguintes tratamentos: AS: Aveia preta em plantio direto sobre palhada do híbrido sorgo sudão; AM: Aveia preta em plantio direto sobre palhada de milheto; TS: Triticale em plantio direto sobre palhada do híbrido sorgo sudão e; TM: Triticale em plantio direto sobre palhada de milheto.

Tabela 1 - Valores médios mensais de temperaturas máximas (Máx), mínimas (Min) e médias, precipitação pluviométrica e umidade relativa (UR) observados em 2001 durante o período experimental.

\begin{tabular}{lccccc}
\hline \multirow{2}{*}{ Mês/Ano } & \multicolumn{3}{c}{ Temperatura $^{\circ} \mathrm{C}$} & \multirow{2}{*}{$\begin{array}{c}\text { Precipitação } \\
(\mathrm{mm})\end{array}$} & UR(\%) \\
\cline { 2 - 3 } & Máx & Mín & Média & & \\
\hline Junho & 26,3 & 12,9 & 18,8 & 5,0 & 73,0 \\
Julho & 28,1 & 13,2 & 20,0 & 2,6 & 64,9 \\
Agosto & 28,9 & 14,0 & 21,0 & 61,0 & 57,3 \\
Setembro & 29,7 & 16,4 & 22,4 & 27,3 & 61,2 \\
\hline
\end{tabular}

Fonte: Estação Meteorológica - FCAV/UNESP - Jaboticabal, 2001. 
A semeadura foi realizada no dia 04/06/2001 com a semeadora-adubadora de plantio direto utilizando-se a densidade de semeadura de $60 \mathrm{~kg} / \mathrm{ha}$ de aveia preta e $40 \mathrm{~kg} /$ ha de triticale (cultivar CB02) em plantio direto. Para adubação de semeadura utilizou-se $20 \mathrm{~kg} / \mathrm{ha}$ de $\mathrm{N}$ (uréia); $30 \mathrm{~kg} / \mathrm{ha}$ de $\mathrm{P}_{2} \mathrm{O}_{5}$ (superfosfato simples) e $10 \mathrm{~kg} / \mathrm{ha}$ de $\mathrm{K}_{2} \mathrm{O}$ (cloreto de potássio). Após 45 dias da semeadura (18/06/2001) realizouse a adubação de cobertura com $20 \mathrm{~kg} / \mathrm{ha}$ de nitrogênio distribuído a lanço, utilizando-se como fonte à uréia.

A área experimental foi irrigada por aspersão com 60 mm de lâmina d'água mensais, cuja distribuição foi de $15 \mathrm{~mm}$ semanais em aplicação única, visando garantir uma adequada formação do estande e rebrota das plantas. A irrigação foi quantificada com base nos dados obtidos em experimentos anteriores realizados no setor de Forragicultura da FCAV/UNESP.

Anteriormente à entrada dos animais, foram realizadas duas avaliações (06/08 e 14/09/2001) medindo-se a altura das plantas e a massa de forragem acumulada, através da amostragem de quatro áreas de $1 \mathrm{~m}^{2}$ em cada parcela.

Para a determinação da quantidade de forragem disponível, considerando a massa de forragem antes da entrada dos animais, foi lançado um quadrado de $1 \mathrm{~m}^{2} \mathrm{e}$ cortou-se, com uso de cutelo, a altura de $0,2 \mathrm{~m}$ do solo. Após o corte, a forragem foi pesada e, posteriormente, levada à estufa de circulação forçada de ar a $55^{\circ} \mathrm{C}$ para a determinação da pré-secagem.

Após a pré-secagem, a forragem foi moída em moinho tipo Wiley em peneira de $1 \mathrm{~mm}$ e, posteriormente analisada, determinando-se os teores da matéria seca (MS), proteína bruta (PB), fibra em detergente neutro (FDN), fibra em detergente ácido (FDA), lignina e digestibilidade in vitro da matéria seca (DIVMS), segundo métodos descritos por Silva \& Queiroz (2002). O teor de hemicelulose foi estimado pela diferença da porcentagem de FDN e de FDA.
Estabeleceu-se como critério para a entrada dos animais para a realização dos pastejos das gramíneas de inverno o momento em que as plantas atingiram a altura média do relvado de $0,6 \mathrm{~m}$ e a retirada dos animais, quando a altura do resíduo apresentasse altura do resíduo média de 0,2 $\mathrm{m}$ para as gramíneas de inverno.

Das amostragens foram obtidos os teores de matéria seca disponível e a partir destes valores foi determinada uma lotação média instantânea, disponibilizando para cada animal 5\% de matéria seca do seu peso (média de $450 \mathrm{~kg}$ ). Nestes parâmetros foi obtida uma lotação média instantânea para os pastejos de 85 UA ha/dia. Considerando-se um período de descanso de 35 dias após os pastejos, a lotação média para as forrageiras utilizadas foi de 2,4 UA/ha.

Após as saídas dos animais, em cada ciclo de pastejo, foram realizadas adubações de cobertura a lanço em toda área experimental, utilizando-se $20 \mathrm{~kg} / \mathrm{ha}$ de nitrogênio, usando-se como fonte de adubo a uréia.

$\mathrm{O}$ experimento foi conduzido segundo o delineamento experimental de blocos casualizados, em arranjo de parcelas subdivididas, sendo analisadas nas parcelas as espécies forrageiras e nas sub-parcelas as épocas de pastejo, com quatro repetições.

Os dados obtidos foram analisados estatisticamente utilizando o programa estatístico ESTAT (V. 2.0) desenvolvido pelo Departamento de Estatística da FCAV, campus de Jaboticabal/UNESP e a comparação das médias pelo teste de Tukey, em nível de 5\% de probabilidade.

\section{RESULTADOS E DISCUSSÃO}

Na Tabela 2 são apresentados os valores de rendimento de matéria seca (RMS) da aveia preta e de triticale semeados em plantio direto sobre palhadas de milheto (M) e sorgo sudão (S), avaliados em dois pastejos.

Tabela 2 - Rendimento de matéria seca (RMS), t/ha, da aveia preta (A) e triticale (T) semeadas em plantio direto sobre palhadas de milheto $(\mathrm{M})$ ou de sorgo sudão $(\mathrm{S})$.

\begin{tabular}{cccccc}
\hline \multirow{2}{*}{ Pastejo } & \multicolumn{3}{c}{ Tratamentos } & \multirow{2}{*}{ Média } \\
\cline { 2 - 5 } & AM & AS & TM & TS & $2,15 \mathrm{~A}$ \\
$06 / 08$ & 1,92 & 2,44 & 1,85 & 2,38 & $1,71 \mathrm{~B}$ \\
$14 / 09$ & 1,73 & 1,82 & 1,63 & 1,67 & 3,86 \\
Total & 3,65 & 4,26 & 3,48 & 4,05 & $2,02 \mathrm{a}$ \\
Média & $1,82 \mathrm{a}$ & $2,13 \mathrm{a}$ & $1,74 \mathrm{a}$ & \multicolumn{3}{c}{ CV para subparcelas: 30,03} \\
\hline \multicolumn{2}{c}{ CV para parcelas: 23,94} & & &
\end{tabular}

Médias seguidas de mesmas letras, minúsculas nas linhas e maiúsculas nas colunas, não diferem (P>0,05) pelo teste de Tukey. AM: aveia preta em plantio direto sobre palhada de milheto; AS: aveia preta em plantio direto sobre palhada de sorgo sudão; TM: triticale em plantio direto sobre palhada de milheto; TS: triticale em plantio direto sobre palhada de sorgo sudão. 
A análise dos dados da Tabela 2 evidencia que as diferentes forrageiras produziram quantidades semelhantes de matéria seca $(\mathrm{P}>0,05)$. Em relação aos pastejos, observou-se queda significativa entre as médias de rendimento do primeiro para o segundo pastejo.

A diminuição na RMS foi causada pelo estádio de desenvolvimento avançado das plantas por ocasião do primeiro pastejo , o que acarretou a eliminação dos meristemas apicais, prejudicando a rebrota.

Além deste fato, pode-se considerar que outros fatores influenciaram na RMS, destacando-se o aumento acentuado da temperatura (Tabela 1) observado durante o período experimental, causando emborrachamento e florescimento precoce das plantas, principalmente no triticale. A indução do florescimento reduziu o período de crescimento vegetativo das plantas.

Os valores de RMS observados no presente estudo para a aveia são superiores aos registrados por Rodrigues \& Godoy (2000) que obtiveram média de 3,2 t/ha em quatro avaliações de amostragem trabalhando com a cultivar São Carlos, e por Seixas (2001) que obteve produção média em dois cortes de 3,4 t/ha, estudando os cultivares São Carlos, UPF87111, UPF86081, UFRGS-7 e preta.

Os teores de proteína bruta (PB) da aveia preta e do triticale avaliados em diferentes pastejos podem ser visualizados na Tabela 3 .

A análise dos dados evidencia que os teores de $\mathrm{PB}$ decresceram $(\mathrm{P}<0,05) \mathrm{em}$ todas as forrageiras colhidas no período do segundo pastejo. Em relação às forrageiras, foram observados menores teores de $\mathrm{PB}(\mathrm{P}<0,05)$ para o triticale no segundo pastejo.

Cumpre destacar que os teores de PB observados nas forrageiras de aveia e de triticale, colhidas nas diferentes épocas, são maiores do que o valor mínimo preconizado por Noller (1997) de 12\%, para que ocorra eficiência no ganho de peso e na lactação dos animais, dependendo do nível de produção esperado. Os valores de PB obtidos foram superiores aos encontrados por Villaça (1991), que obteve média de $14,42 \%$ de PB trabalhando com as cultivares UPF2, UPF3, UPF7 e preta colhidas em diferentes épocas, em cultivo de aveias pretas e brancas, em Jaboticabal-SP e inferiores aos verificados por Rodrigues \& Godoy (2000), que encontraram valor médio de PB de $18,75 \%$ com a cultivar São Carlos, em pastejo restringido em aveias preta e branca na região de São Carlos. Trabalho conduzido por Seixas (2001) avaliando genótipos de aveia preta e branca, para a produção de forragem, obteve um teor médio de proteína bruta de $15,9 \%$, semelhante ao presente estudo.

Na Tabela 4 estão apresentados os valores de FDN, FDA, hemicelulose e lignina da aveia preta e triticale ( $\mathrm{T}$ ) em função do manejo adotado. Verifica-se que os teores médios de FDN aumentaram $(\mathrm{P}<0,05)$ para todas as forrageiras no segundo pastejo. Em relação as forrageiras, foram observados maiores teores médios de $\mathrm{FDN}(\mathrm{P}<0,05)$ para o triticale tanto sobre a palhada de milheto quanto na palhada de sorgo sudão.

Em relação aos teores de FDA, observou-se que a aveia preta, tanto área sob milheto como sorgo sudão apresentaram menores $(\mathrm{P}<0,05)$ valores desta fração comparado com o triticale semeado nas mesmas áreas. Nos pastejos, maiores valores $(\mathrm{P}<0,05)$ foram evidenciados no primeiro pastejo.

Quanto aos teores de hemicelulose (Tabela 4) a aveia preta estabelecida sobre a palhada de sorgo sudão apresentou menos teor $(\mathrm{P}<0,05)$ desta fração comparado com o triticale semeado em área cultivada anteriormente com sorgo sudão, não havendo diferença para os demais tratamentos.

Tabela 3 - Teores de proteína bruta $(\mathrm{PB}), \%$, da aveia preta $(\mathrm{A})$ e de triticale $(\mathrm{T})$ semeados em plantio direto sobre palhadas de milheto (M) ou de sorgo sudão (S).

\begin{tabular}{|c|c|c|c|c|c|}
\hline \multirow{2}{*}{ Pastejo } & \multicolumn{4}{|c|}{ Tratamentos } & \multirow{2}{*}{ Média } \\
\hline & $\mathrm{AM}$ & AS & TM & TS & \\
\hline $06 / 08$ & 17,7 & 17,6 & 16,3 & 17,7 & $17,3 \mathrm{~A}$ \\
\hline $14 / 09$ & 16,1 & 16,1 & 12,2 & 13,5 & $14,6 \mathrm{~B}$ \\
\hline Média & $16,9 \mathrm{a}$ & $16,9 \mathrm{a}$ & $15,6 \mathrm{ab}$ & $14,4 \mathrm{~b}$ & \\
\hline \multicolumn{2}{|c|}{ CV para parcelas: 8,54} & & & $\mathrm{SV}$ para $\mathrm{s}$ & 9,8 \\
\hline
\end{tabular}

Médias seguidas de mesmas letras, minúsculas nas linhas e maiúsculas nas colunas, não diferem $(\mathrm{P}>0,05)$ pelo teste de Tukey. AM: aveia preta em plantio direto sobre palhada de milheto; AS: aveia preta em plantio direto sobre palhada de sorgo sudão; TM: triticale em plantio direto sobre palhada de milheto; TS: triticale em plantio direto sobre palhada de sorgo sudão. 
Tabela 4 - Teores de componentes da fração fibrosa da aveia preta (A) e triticale (T) semeadas em plantio direto sobre palhadas de milheto $(\mathrm{M})$ ou de sorgo sudão $(\mathrm{S})$.

\begin{tabular}{|c|c|c|c|c|c|}
\hline \multicolumn{6}{|c|}{ FDN (\% na MS) } \\
\hline Pastejo & $\mathrm{AM}$ & AS & TM & TS & Média \\
\hline $06 / 08$ & 50,80 & 50,68 & 58,18 & 57,61 & $54,31 \mathrm{~B}$ \\
\hline $14 / 09$ & 53,56 & 52,85 & 62,86 & 63,28 & $58,14 \mathrm{~A}$ \\
\hline Média & $52,18 \mathrm{~b}$ & $51,76 \mathrm{~b}$ & $60,52 \mathrm{a}$ & $60,44 \mathrm{a}$ & \\
\hline \multicolumn{2}{|c|}{ CV para parcelas: 6,23} & & & \multicolumn{2}{|c|}{ CV para subpacelas: 8,85} \\
\hline \multicolumn{6}{|c|}{ FDA (\% na MS) } \\
\hline $06 / 08$ & 27,68 & 30,25 & 33,89 & 31,32 & $30,79 \mathrm{~A}$ \\
\hline $14 / 09$ & 22,29 & 21,51 & 28,08 & 29,21 & $25,27 \mathrm{~B}$ \\
\hline Média & $24,99 \mathrm{~b}$ & $25,88 \mathrm{~b}$ & $30,26 \mathrm{a}$ & $30,98 \mathrm{a}$ & \\
\hline \multirow{2}{*}{\multicolumn{2}{|c|}{ CV para parcelas: 10,41}} & & & \multicolumn{2}{|c|}{ CV para subpacelas:11,66 } \\
\hline & & \multicolumn{4}{|c|}{ Hemicelulose (\% na MS) } \\
\hline $06 / 08$ & 23,11 & 20,42 & 24,27 & 26,29 & $23,52 \mathrm{~B}$ \\
\hline $14 / 09$ & 31,27 & 31,33 & 34,78 & 35,24 & $33,16 \mathrm{~A}$ \\
\hline Média & $27,19 \mathrm{ab}$ & $25,88 \mathrm{~b}$ & $29,53 \mathrm{ab}$ & $30,77 \mathrm{a}$ & \\
\hline \multicolumn{2}{|c|}{ CV para parcelas: 9,97} & & & \multicolumn{2}{|c|}{ CV para subpacelas: 10,34} \\
\hline \multicolumn{6}{|c|}{ Lignina (\%na MS) } \\
\hline $06 / 08$ & $3,72 \mathrm{Aa}$ & $3,70 \mathrm{Aa}$ & $3,94 \mathrm{Ba}$ & $3,70 \mathrm{Ba}$ & 3,71 \\
\hline $14 / 09$ & $4,50 \mathrm{Ab}$ & $4,23 \mathrm{Ab}$ & 6,36Aa & $5,12 \mathrm{Ab}$ & 5,05 \\
\hline Média & 4,11 & 3,96 & 5,15 & \multirow{2}{*}{\multicolumn{2}{|c|}{$\frac{4,41}{\text { CV para subpacelas: } 13,01}$}} \\
\hline $\mathrm{CV}_{1}$ & as: 15,85 & & & & \\
\hline
\end{tabular}

Médias seguidas de mesmas letras, minúsculas nas linhas e maiúsculas nas colunas, não diferem $(\mathrm{P}>0,05)$ pelo teste de Tukey. AM: aveia preta em plantio direto sobre palhada de milheto; AS: aveia preta em plantio direto sobre palhada de sorgo sudão; TM: triticale em plantio direto sobre palhada de milheto; TS: triticale em plantio direto sobre palhada de sorgo sudão.

A análise relativa à época de avaliação evidenciou maiores valores $(\mathrm{P}<0,05)$ de FDN para a forragem colhida no segundo pastejo, de FDA para a forragem colhida no primeiro pastejo e de hemicelulose para a forragem colhida no segundo pastejo. Ressaltase, no entanto, que no segundo pastejo as plantas se encontravam em estádio reprodutivo avançado, apresentando inflorescência com sementes, o que certamente diluiu a fração fibrosa.

Em relação ao triticale, observou-se no segundo pastejo que os animais rejeitaram as inflorescências, provavelmente em decorrência do conteúdo de sílica das mesmas. Este comportamento foi também verificado por Stallknecht et al. (1996) e Varughese et al. (2002) em estudo com a mesma espécie. Os dados observados relativos aos teores de FDN, foram superiores aos obtidos por Rodrigues \& Godoy (2000) que obtiveram valor médio de FDN de $51,5 \%$ no cultivar São Carlos.

Houve interação na análise dos teores de lignina (Tabela 4) demonstrando que não ocorreu variação significativa entre as forrageiras no primeiro pastejo, sendo estes $(\mathrm{P}<0,05)$ menores quando comparados com a avaliação no segundo pastejo. Na segunda avaliação os tratamentos em que a principal forrageira foi a aveia preta, os valores de lignina foram significativamente menores do que nos tratamentos que apresentavam triticale com forrageira principal. Esta variação deve-se ao fato de que na segunda época de avaliação os tratamentos com triticale apresentavam elevado número de plantas em estádio reprodutivo avançado, ocasionando assim uma maior lignificação do caule, característica que influenciou na avaliação com relação às épocas de corte. Os valores encontrados para lignina são semelhantes aos obtidos por Seixas (2001) com valor médio de 4,55\% obtido em dois cortes com os cultivares São Carlos, UFRGS-7, UPF87111, UPF86081 e preta.

$\mathrm{Na}$ Tabela 5 estão relacionados os dados de digestibilidade in vitro da matéria seca (DIVMS). Pode-se observar que somente o tratamento constituído por aveia preta em plantio direto em milheto diferiu dos demais no primeiro pastejo, apresentando 70,05\% de DIVMS. No segundo pastejo, os tratamentos com aveia apresentaram maior digestibilidade $(77,94$ e $78,04 \%)$ do que os tratamentos com triticale $(64,33$ e $67,35 \%)$. 
Associando-se os valores de DIVMS (Tabela 5) com os valores de parede celular (Tabela 4) obtidos no presente experimento, nota-se que no segundo pastejo os maiores teores de parede celular nos tratamentos com triticale influenciaram a digestibilidade da forragem que diferiu dos valores obtidos na primeira avaliação.

Os valores de DIVMS obtidos foram superiores aos observados por Villaça (1991), que foi em média 66,95\% em estudo de diferentes épocas de pastejo utilizando as cultivares UPF2, UPF3, UPF7 e preta, e por Seixas (2001), que encontrou DIVMS média de 60,6\% pesquisando as aveias São Carlos, UFRGS7, UPF87111, UPF86081 e Preta em dois cortes, todos os experimentos conduzidos em Jaboticabal - SP.

\section{CONCLUSÕES}

O rendimento de matéria seca das pastagens foi semelhante e, em relação às épocas de avaliação observouse menor rendimento no segundo corte.

Para a composição química das forrageiras de inverno observou-se maiores teores de PB e de FDA na forragem colhida no primeiro corte e de hemicelulose no segundo corte, enquanto os valores de FDN não foram diferentes. A forragem de triticale apresentou menor conteúdo de PB e maiores teores de constituintes da parede celular.

O rendimento de aveia preta e de triticale sob irrigação é uma alternativa viável para o período seco do ano, devido a sua produtividade e composição química.

\section{REFERÊNCIAS BIBLIOGRÁFICAS}

ALVIM, M. J.; MARTINS, C. E. Efeito da densidade de semeadura sobre a produção de matéria seca de aveia e do azevém em culturas puras ou consorciadas. Revista da Sociedade Brasileira de Zootecnia, Viçosa, v. 15, n. 14, p. 285-296, 1986.

ANDRIOLI, I.; CENTURION, J. F. Levantamento detalhado dos solos da Faculdade de Ciências Agrárias e Veterinárias de Jaboticabal. In: CONGRESSO BRASILEIRO DE CIÊNCIA DO SOLO, 27., 1999, Brasília. Anais... Brasília, DF: SBCS, 1999. p. 32.

CARDOSO, R. M. Culturas forrageiras de inverno e sua utilização. In: SIMPÓSIO SOBRE MANEJO DE PASTAGENS, 2., 1977, Piracicaba. Anais... Piracicaba: ESALQ, 1977.p. 104-119.

COMISSÃO SUL BRASILEIRADE PESQUISADAAVEIA. Recomendação da Comissão Sul brasileira de pesquisa da aveia 1991/1992. Passo Fundo: Faculdade de Agronomia, 1991. 43 p. 
FLOSS, E. L. Manejo forrageiro de aveia (Avena $s p$ ) e azevém (Lolium $s p$ ). In: SIMPÓSIO SOBRE MANEJO DE PASTAGENS, 9., 1988, Piracicaba. Anais... Piracicaba: FEALQ, 1988. p. 231-268.

GODOY, R.; NEGREIROS, G. F.; BATISTA, L. A. R. Avaliação de linhagens promissoras de aveia para a produção de grãos e forragem em São Carlos, SP, Brasil. São Carlos: Embrapa Pecuária Sudeste, 1992.

LEITE, N. Culturas forrageiras não convencionais e sua utilização. In: CONGRESSO BRASILEIRO DE FORRAGICULTURA, 1986, Piracicaba. Anais... Piracicaba: FEALQ, 1986. p. 49-78.

MARSCHNER, H. Mineral nutrition of higher plants. New York: Academic, 1986. 403 p.

NOLLER, C. R. Nutritional requirements of the grazing animal. In: SIMPÓSIO INTERNACIONAL SOBRE PRODUÇÃO ANIMAL EM PASTEJO, 1., 1997, Viçosa. Anais... Viçosa: UFV, 1997. p. 145-172.

PEREIRA, J. P. Forrageira de inverno. Informe Agropecuário, Belo Horizonte, v. 13, n. 152, p. 54-62, 1988.

REIS, R. A.; RODRÍGUEZ, L. R. A.; DÉZEN, P. A. Rendimento e qualidade da forragem de genótipos de aveia semeados em diferentes épocas. Revista Brasileira de Zootecnia, Viçosa, v. 22, n. 4, p. 642-650, 1993.
RODRIGUES, A. A.; GODOY, R. Efeito do pastejo restringido em aveia sobre a produção de leite. Pesquisa Agropecuária Brasileira, Brasília, v. 35, n. 3, p. 551-556, 2000.

SEIXAS, P. F. Avaliação da aveia preta e de genótipos de aveia amarela para produção de forragem e de grãos. 2001. 46 f. Monografia (Graduação em Agronomia) Universidade Estadual Paulista, Jaboticabal, 2001.

SILVA, D. J.; QUEIRÓZ, A. C. Análise de alimentos métodos químicos e biológicos. Viçosa: UFV, 2002. 235 p.

STALLKNECHT, G. F.; GILBERTSON, K. M.; RANNEY, J. E. Alternative wheat cereal as food grains: einkorn, emmer, kamut and triticale. In: JANICK, J. Progress in new crops. Alexandria: ASHS, 1996. p. 156-170.

VARUGHESE, G.; PFEIFFER, W. H.; PENA, R. J. Triticale: a reappraisal. Cereal Foods World, [S.1.], v. 41, n. 6/7, 2002. Disponível em: <http://www.worldbank.org/html/cgir/ newsletter/april97/8tritic.html>. Acesso em: 28 fev. 2002.

VILELA, H. Aveia como volumoso para vacas em lactação. Informe Agropecuário, Belo Horizonte, v. 7, n. 78, p. 38-40, 1981.

VILLAÇA, M. Produção de matéria seca, composição química e digestibilidade in vitro da aveia preta colhidas em diferentes épocas. 1991. 45 f. Monografia (Graduação em Zootecnia) - Universidade Estadual Paulista, Jaboticabal, 1991. 